\title{
Del vacío instante
}

\section{On the inciting void}

\author{
Félix DUQuE \\ Universidad Autónoma de Madrid \\ felix.duque@uam.es
}

\section{Resumen}

El título de este ensayo requiere una traducción doble en el idioma inglés: sugiere en efecto que, en la obra de Chillida, the empty instant es el resultado o consecuencia de the inciting void (trasmutando de este modo sustantivo y adjetivo del título original). La escultura de Chillida no puede clasificarse ni como figurativa (o mimética, en general), ni como abstracta (como en los purismos de la vanguardia). La filosofía que subyace a su obra no se pliega al mundo griego (en el cual: "téchne es con mucho más débil que Ananke"; Esquilo, Prom. 511) ni al mundo moderno (en el cual: "el arte es producción... por arbitrio, a cuyas acciones subyace la razón”; Kant, Crítica del Juicio, § 43). Previa a esa distinción sigue restando una acción primordial: la de la mano como ofrecimiento de lugares, recibida por el mundo como entramado de medidas. El latente doble título (instante es el participio presente de "instar"; vacío es la acción de vaciar: no tanto casting cuanto hollow out). Así, la obra de Chillida es literalmente liminar: abre al mundo mientras está en el mundo, como si de la piel de la piedra o el hierro se tratase. Dejar ver el vacío (void) in actu exercito y en el instante significa pues dejar ser a las cosas como lugares de un mundo histórico: el mundo de nuestros padres.

Palabras clave: vacío, vaciedad, ahuecamiento (no: vaciado), arte como resolución (dejar ser al espacio-tiempo-del-juego), mundo histórico (como localidad de lugares. 


\section{Abstract}

The title of this essay requires a double translation in English: it suggests that, in Chillida's work, the empty instant is a result or consequence of the inciting void (thus, interchanging the noun and the adjective in the original title). Chillida's sculpture cannot be classified neither as figurative (or mimetic, in general) nor as abstract (such as in the purism of the avant-garde). The philosophy underlying his work doesn't belong to the Greek world (in which "téchne is much weaker than anánke", Aeschylus, Prom. v. 511), but neither to the modern world (in which "art is a production... by free will, under which reason lies"; Kant, Critique of pure reason, § 43). Before this distinction an originary, primordial action may be found: the action of the hand offering places, received by a world conceived as intertwinning of measures. This latent double title (inciting is the present participle of the verb "to incite": void is the result of the action of emptying, not understood as casting, but as hollowing out). Thus, Chillida's work is literally liminary: it opens the world while being in the world, as if it was the stone's or iron's skin. To allow the void to be seen in actu exercito and at every inciting instant means to let the things be as places of a historical world: our fathers' world.

Key words: Void, emptyness, hollowing out, art as Erschlossenheit (to let the time-space-game be), historical world (as locality of places).

El modo ambiguo con que la prolífica obra de Eduardo Chillida ha sido y sigue siendo recibida no representa desde luego un caso único en la plástica contemporánea, oscilante como se halla esa recepción entre la fascinación de quienes se acercan a ella sin prejuicios, dejándose impresionar por la furia suave de su reciedumbre ingrávida y de su presencia rotunda y a la vez como esquiva, y la innegable desconfianza y hasta repulsa que suscita en algunos viandantes que se tropiezan con sus grandes esculturas urbanas. Esa ambivalencia se viene produciendo al menos desde la aparición de las vanguardias, ya en el siglo XIX, acrecentada por la revolución en la escultura no figurativa de la primera mitad del siglo XX, con figuras como Julio González, Antoine Pevsner o Alexander Calder, entre otros. Y sin embargo, como veremos, hay algo en Chillida (y en su gran antagonista cordial: Jorge Oteiza) que lleva a exacerbación la fascinación y a exasperación la repulsa, y que desde luego lo separa de las vanguardias, de las que en modo alguno puede considerarse epígono, sino más bien -diríamos- heredero subversivo o "a la contra". 
Con respecto a la extrañeza y aun animadversión suscitada por las artes plásticas en general (y no sólo por la obra de Chillida), lo primero que cabe decir es que ello se debe a una suerte de efecto inercial -y que opera a las veces inconscientemente- en quienes todavía no han asimilado eso que, en un plano estrictamente filosófico (sin entrar por ende en complejos sentimientos religiosos), podemos llamar con Nietzsche la muerte de Dios, e.d., la pérdida de la trascendencia o de paradigmas ultramundanos o metafísicos (cifrados en la tríada de los trascendentales verum, bonum, pulchrum) y, por consiguiente, de toda imaginería, que convertía a las artes figurativas en fuente de representaciones alegóricas al servicio del poder religioso o político: triunfo, en suma, del significado (la esencia), que haría acto de presencia a través del significante (como supuesta copia del mismo). Ello, naturalmente, con independencia de los valores que hoy, tras el eclipse de lo divino (no, ciertamente, de lo sagrado), puedan encontrarse en las grandes obras medievales o renacentistas relativas a la Pasión de Cristo, por ejemplo.

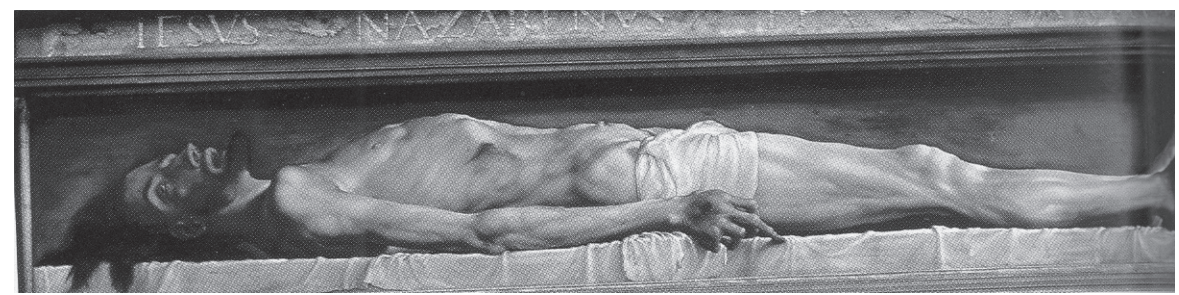

Hans Holbein. Cristo muerto

Pues bien, aun cuando parezca que con ello damos un gran salto (y hasta realicemos una ilícita metábasis eis allò génos), creo que la persistencia de una actitud literalmente premoderna y de "platonismo para el pueblo", en una palabra: la persistencia de una cosmovisión tradicional, sigue siendo la responsable de esa inquina contra las artes plásticas: no hace falta ser un hegeliano de estricta observancia para darse cuenta de que precisamente quienes se jactan de atenerse a lo concreto y a los hechos desnudos son quienes más abstractamente piensan; pero no - esta vez contra Hegel- porque se aferren a lo sensible y se nieguen a la destrucción dialéctica de lo real, sino, muy al contrario, porque confunden eso que ellos llaman "cosas concretas", mostrencas y de bulto, con la nuda presencia de lo sensible, sin más, esto es: sin recurso a un significado que la obra de arte encarnara de algún modo.

Esa actitud radicalmente abstracta es la responsable de la pregunta, tantas veces formulada: "Pero, ¿qué significa esto?” Una exclamación desde luego retórica, porque la obra ya está juzgada y condenada de antemano. Esos tales 
están repitiendo y a la vez paliando (en ambos casos, sans le savoir) la crítica de Platón a la zoographia ("descripción de lo viviente")', ya que, para elevarse a aquello que viene significado por la obra, necesitan de lo mimético. Y quizá con más razón cabría apelar en este caso a Aristóteles, ya que aquellos que sólo en cuanto imaginero admiten a un artista abrigan en el fondo la misma convicción que Miguel Ángel: entresacar la idea (ê̂dos) o la forma pura -armónica, geométrica, bella- aprisionada en la materia ruda² .

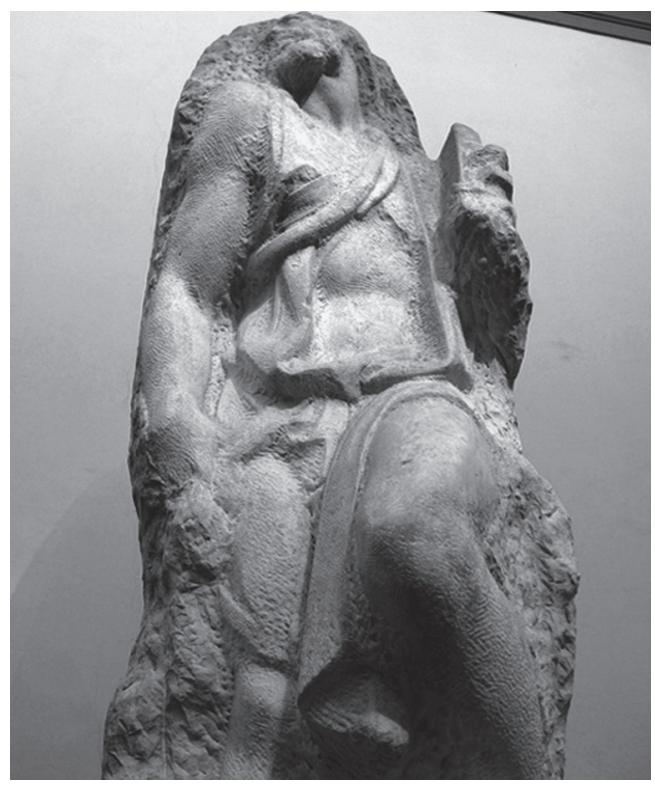

Miguel Ángel. I Prigioni (Florencia)

Así pues, el que pregunta: “QQué significa eso?”, aparte de elevar su particular ego homuncio a juez y árbitro de las artes, no hace sino vaciar sobre el cuadro o la escultura un saco de prejuicios representacionalistas y figurativos.

\footnotetext{
${ }^{1}$ Republica. X, 603b: "la pintura y todo arte arte imitativo (graphikè kaì hólos he mimetikè) hacen sus trabajos a gran distancia de la verdad", porque copian la apariencia de las cosas sensibles, perecederas, y encima utilizan para ello los sentidos, "esa parte nuestra que se aparta de la razón (pórro d'aû phronéseos)". De manera que "una cosa vil, ayuntada a lo vil" no puede sino conducir a la inesquivable condena: "sólo lo vil es engendrado por la mimetiké".

${ }^{2}$ De ahí también la preferencia de Miguel Ángel por la escultura, en detrimento de la pintura, como se expresa polémicamente en carta a Benedetto Varchi: "Io dico che la pittura mi par più tenuta buona quanto più va verso il rilievo, et il rilievo più tenuto cattivo quanto più va verso la pittura." (En Varchi, B. y Borghini, V., Pittura e Scultura nel Cinquecento, a cura di P. Barochi, Sillabe, Livorno 1998, p. 84). Y es que la escultura imitaría más fielmente la naturaleza interna de lo representado, sin caer además en el añadido falaz de los colores -propio de la pintura-, y que empañaría la nobleza sublime de una idealizada corporeidad.
} 
Triunfo y fracaso de la mímesis: pues en efecto, diríase que lo que este inquisidor pretende es ser de veras platónico, o sea: llegar a la idea pura, al significado ideal, puesto que no se conforma con la contemplación de la imagen, sin más.

Por su parte, quien pregunta: “¿Qué quiere decir esto?”, se acuesta más del lado del idealismo (también en muchos casos, por descontado, sin saberlo) ${ }^{3}$, dado que la obra debería ser un mero vehículo (un signo transparente) para la dicción de lo que en ella se expresa. Por cierto, quizá no sería descabellado pensar -y con ello empezamos pedem aliquantulum a separar a Chillida de buena parte de la plástica contemporánea- que las mentadas vanguardias, y sobre todo en su vertiente purista (unas manifestaciones artísticas que difícilmente podríamos considerar ya como contemporáneas), no habrían hecho sino llevar hiperbólicamente al extremo lo contenido in nuce en la "ingenua" interrogación sobre lo que una obra querría decir. Pues ya no se trataría de entresacar la forma oculta natural a partir de la ganga de lo sensible, sino de encontrar esa forma en el interior del espíritu del propio artista, en una curiosa coyunda de racionalismo (con sus "ideas innatas") y de lógica de la producción 4 .

No es extraño entonces que, en esta apenas velada metafísica del sujeto, incluso la denominación de las artes espaciales se modifique, dejando éstas de ser tenidas por "artes imagineras" (en alemán: bildende Künste) para que el arte espacial -ya en singular- sea considerado en cambio como "arte de la figura [o de la configuración]" (gestaltende Kunst) ${ }^{5}$. En consecuencia, la escultura deja de ser vista (en alemán) como Bildhauerei (literalmente: "imagine-

\footnotetext{
${ }^{3}$ La crítica más implacable que se haya hecho a la sensibilidad (aunque habría que decir, más bien: a un realismo ingenuo disfrazado de creencia en lo sensible) se encuentra en el cap. I de la Fenomenología del espíritu, cuando, tras desmontar las creencias de la "opinión" o Meinung, Hegel sentencia: "Pero el lenguaje es [...] más de verdad [que lo que opina la sensibilidad]" (Die Sprache aber ist [...] das wahrhaftere). Phänomenologie des Geistes, Meiner, Hamburgo, 1980. G.W. 9: 65 20 (hay tr. esp. de A. Gómez. Abada, Madrid, UAM, 2010, p. 167).

${ }^{4}$ Hans (o Jean) Arp, uno de los mejores representantes de las vanguardias, propondrá al respecto una suerte de Manifiesto, en abierto desafío a lo natural: "Nosotros no queremos copiar la naturaleza, ni reproducirla; lo que queremos es producir, producir como la planta que produce un fruto, y no reproducir; queremos producir directamente, y no por mediación" ("Art concret», en On my way. Poetry and Essays, 1912-1947, Nueva York, Wittenborn, 1948, p. 98).

${ }^{5}$ En castellano, esa clara diferencia podría quedar difuminada por el hecho de que bildend y gestaltend podrían verterse en ambos casos como "figurativo". Sin embargo, Bild ("imagen") remite -o remitía - comúnmente a un original, que la imagen reproduciría (de ahí Vorbild: "paradigma", versus Nachbild: "copia"); por el contrario, Gestalt ("figura") implica algo ficticio, el producto de un "poner" o "emplazar" (stellen) por parte del sujeto. Heidegger, como es sabido, acuñará un término cercano: Gestell, para aludir a la esencia de la técnica moderna; cf., p.e.: «La pregunta por la técnica»: "A aquella interprelación que provoca, que coliga al hombre a solicitar lo que sale de lo oculto como existencias, lo llamamos ahora la estructura de emplazamiento (Ge-stell)." (En Conferencias y artículos [traducción de E. Barjau], Barcelona, Serbal, Barcelona 1994, p. 21).
} 
ría") para tomar el neologismo griego: Plastik, la "plástica". También en el término español "escultura" podemos seguir la evolución de un arte que pasará del cerramiento volumétrico Ya sea un volumen macizo, lo propio del escultor de la piedra: el lithógraphos; o superficial y hueco, como el de quien se dedica a la escultura en bronce: el chalkógraphos) al espaciamiento del vacío. Etimológicamente, "esculpir" remite a tres raíces que compendian muy bien las tres funciones de la escultura: incidir (en el sentido de realizar un corte o incisión), hendir (rajar, separar) y excavar ${ }^{6}$.

Por el contrario, la plástica ${ }^{7}$ parece oficio más de alfarero que de imaginero, pues que pretende moldear arbitrariamente un material plástico con la mínima resistencia por parte de éste. Tal es, y no por azar, la definición que en las postrimerías del siglo XVIII ofrece Immanuel Kant de Kunst ("arte", pero en esa época, también "técnica"): "producción por libertad, esto es por un arbitrio a cuyas acciones subyace la razón". ${ }^{8}$ Si llevamos ahora consecuentemente al extremo esta compenetración de la producción, la libertad y la razón, no nos resultará extraño en absoluto el programa común de las distintas vanguardias, a saber: la tendencia a minimizar (y en el límite, a suprimir) el aparecer sensible, en beneficio de la abstracción (Kandinsky), del empleo sistemático de una geometría reductiva (Mondrian, van Doesburg) o de una descomposición cubista (Picasso, Braque) o minimalista (Arp, Schwitters) de la imagen, hasta la decreatio suprematista de un Malevich. Con ello, la materialidad del arte plástico tiende a reducirse a un mero pretexto para sostener una conversión entre espíritus cultos. Así, de manera harto significativa, celebra Kandinsky la irrupción de un arte puramente espiritual, preconizado por Maurice Maeterlinck (en De la belleza interior), cuyas palabras cita el pintor con entusiasmo: "No hay nada sobre la tierra que con tanta ansia (begieriger) se incline a la belleza y se embellezca con tanta facilidad como el alma... Por ello, hay pocas almas en la tierra que se resistan al dominio (Herrschaft) de un alma entregada a la belleza".

\footnotetext{
${ }^{6}$ Respectivamente, 1) raíz [s]kl-*: "hacer incisiones, dejar trazos en una materia dura", de donde sculpo, en latín; 2) *[s]kel-: "rajar, escindir", de donde scalprum: el instrumento con que se labra o raspa una materia dura, con su diminutivo scalpellum, del que resultan "escoplo" y "escalpelo"; y en fin, 3) *skab-: "escarbar, excavar y cavar", de donde scabo y skápto (por ejemplo: dià boôn skáptein, significa "cavar con ayuda de los bueyes, labrar").

${ }^{7}$ Una sustantivación del adj. gr. plastiké [téchne], a su vez del verbo plássein: dar forma a una materia blanda, como la arcilla o la cera; de ahí "plasmar" y "plasma" (lo cual está bien cercano al lat. fictor y al. der Gestalter: "el hacedor"; ver supra, nota 5).

${ }^{8}$ Kritik der Urtheilskraft § 43. En Werke. Akademie Textausgabe, Berlín, De Gruyter, 1968; V, 303.

${ }^{9}$ Kandinsky, W., Über das Geistige in der Kunst (1911; fecha de publicación: 1912), Berna, Benteli Verlag, $1970^{\circ}$, p. 137.
} 
En este proceso (no en vano coetáneo del futurismo y de su alabanza de la máquina), la materia, en su plasticidad, tiende cada vez más a convertirse en producto sintético, de laboratorio, mientras que en las artes esa progresiva "buena disposición" de una materia fabricada ad hoc recuerda cada vez más a la chôra platónica (y consecuentemente, a su gran Ordenador y Hacedor: el Demiurgo). Algo que convendría a los rasgos de esa materia "caótica" descrita -de un modo tan adecuado al prejuicio moderno como etimológicamente incorrecto- por Schelling ya en 1842, al comentar el inicio del proceso cosmogónico en la la Teogonía de Hesíodo:

"Al principio fue Caos". En la voz de procedencia (cháo, chaíno, chátso) se halla la noción del retroceso a las profundidades, del alumbramiento (Aufgethanseyns), del estar en franquía (Offenstehens), una noción que remite empero a la más amplia de "no prestar resistencia“" (algo que sólo ocurre en [el ámbito] de lo concreto). Además, este rasgo negativo presente en su primera noción viene también expresado en el hecho de que en esa palabra se incluye también la representación de la indigencia y de la falta (der Bedürftigkeit, des Mangels) enthalten ist. En razón de esta noción predominante: ausencia de concreción y falta de resistencia, la palabra cháos ha sido también utilizada ulteriormente para el espacio vacio en general (für den leeren Raum überhaupt); [...] en el Timeo, donde Platón habla de la madre y el soporte (Unterlage) de todo lo sensible, [la chôra es] algo completamente invisible y carente de figura (Tim. 51a). ${ }^{10}$

Al cabo de la calle, eso invisible y amorfo se configurará como Vacío, en el sentido de recipiente infinito dado de antemano (sea como sensorium Dei en Newton, o como forma pura de la sensibilidad, en Kant), listo para ser "amueblado" luego con cosas: el mundo como The Furniture of the World ${ }^{11}$ : el espacio se torna así en condición última de mensurabilidad o sea de matematización del mundo.

Sólo que, pace Hesíodo y Platón (al menos en la interpretación habitual, según acabamos de comprobar en Schelling), por no hablar de Newton y Kant, esa inconcreción y esa falta de resistencia no se da en un quantum infinito dado a priori, sino que supone -como la narración mítica de los trabajos de

\footnotetext{
${ }^{10}$ Schelling, F.W.J., Philosophie der Mythologie (26. Vorl.). En Sämmtliche Werke. Ed. Cotta. Stuttgart/Augsburgo 1857; XII, 596.

${ }^{11}$ Así titula Mario Bunge el primer volumen de su Teatise on Basic Philosophy: Ontology, Nueva York, Springer, 1977.
} 
Hércules deja entrever- el resultado final de un gigantesco y arduo proceso de tala y quema, de roza de la ingens sylva trémulamente recordada en la Scienza Nuova de Vico. La matemática y la ontología no son sino abstracciones, el despojo último del cadáver de una naturaleza antes ajena al hombre, y que éste ha debido empezar por dominar abriendo lugares en ella, haciendo sitio. En la etimología del alemán Raum (ingl.: room) subyace este "espaciar" (ausräumen) como "desbrozar" y "desembarazar", abrir claros y dejar en franquía. ${ }^{12} \mathrm{Y}$ es que no hay ni ha habido jamás un espacio "abierto" de antemano, sino que lo han abierto la espada y la llama, el hacha y el arado: violencia primigenia contra una naturaleza sólo apreciada si transfigurada y domesticada por la acción humana: una naturaleza "servicial", rechazada y denostada precisamente por eso -por haber sido transformada para ponerla al servicio de la burguesía- por parte de las vanguardias (repárese en el retorno del bon sauvage en las ensoñaciones "degeneradas" - al decir del nacionalsocialismo- de expresionistas, fauvistas y cubistas respecto de un exotismo "subversivo"). ${ }^{13}$ Triste destino éste, el de una naturaleza otrora "virgen", ahora violada, aburguesada y, por añadidura, despreciada por los artistas de la expresión espiritual. Al respecto,

\footnotetext{
${ }^{12}$ Como es sabido, ésta es la tesis - correcta- sostenida por Martin Heidegger en su célebre conferencia Die Kunst und der Raum, publicada, junto con las Bemerkungen zu Kunst - Plastik - Raum, en ed. trilingüe por la Universidad P blicala Universidad Pública de Navarra. Pamplona 2003. Resulta, sin embargo, asombroso que Heidegger no tenga para nada en cuenta las connotaciones negativas (incluso políticas) de esta noción primitiva del espaciar como un "abrirse paso" y "hacer sitio", según he hecho notar en la $1^{a}$ parte de Arte público y espacio político, Madrid, Akal, 2001.

${ }^{13}$ En la confrontación de cosmovisiones de la primera mitad del siglo XX se produjo al respecto un pasmoso entrecruzamiento de direcciones, junto con un desdoblamiento de tendencias: $y$ así, mientras que las vanguardias se hacían agresivamente "salvajes" en lo artístico, muchos de sus más conspicuos representantes soñaban con el comunismo y el pacifismo universales; un buen ejemplo de ello estaría en Les demoiselles d'Avignon, en donde se exponen prostitutas de la calle Avinyon de Barcelona con rostros que recuerdan fuertemente las máscaras africanas. Por el contrario, cuanto más insistían ideológicamente los jerarcas nacionalsocialistas en el macizo de la sangre y de la tierra y en la glorificación del campesinado, tanto más pompier y cursis eran las tendencias artísticas propiciadas por el régimen. Posiblemente sólo el fascismo italiano fue coherente -por lo menos al inicio, por adherirse al Movimento muchos miembros del futurismo-- Pero tras la toma del poder, el arte oficial se tornó cada vez más kitsch (avant la lettre), como ilustra muy bien el llamado cinema dei telefoni bianchi (sobre todo de 1936 a 1943). Con respecto a la cosmovisión de las vanguardias (la única artísticamente relevante), quien ha sabido expresar mejor la mencionada paradoja ha sido Theodor W. Adorno: "La idea que Kant tuvo del arte era la de servidor del hombre, pero el arte se hace humano desde el momento en que reniega de ese servicio. Su carácter humano (ihre Humanität) es incompatible con cualquier ideología de servicio a los hombres. Su fidelidad a los hombres se conserva únicamente siendo inhumano con ellos (durch Inhumanität gegen sie)." Ästhetische Theorie (Gesammelte Schriften. Suhrkamp. Frankfurt/M. 1970; 7, 292s.). Lyotard ha radicalizado esta posición humanamente "inhumana" en Lo inhumano. Charlas sobre el tiempo (1988), Manantial, Buenos Aires 1998.
} 
es digna de nota la violenta recusación de la naturaleza que un pintor como Franz Marc expone en carta a su mujer en los inicios de la Primera Guerra Mundial, menos de un año antes de morir en el frente: "Desde muy temprano he sentido la "fealdad" del hombre; el animal me parecía más bello, más puro; pero también en él he descubierto tal grado de repulsión y de fealdad que, de una manera instintiva, mis creaciones (Darstellungen) se han ido haciendo (por una suerte de coerción interna) siempre más esquemáticas y abstractas. Un año tras otro, los árboles, el agua me presentaban su aspecto más siniestro, hasta que al fin un día se me apareció la naturaleza en toda su fealdad. Entonces me di cuenta de lo que ella significaba: impureza (Unreinheit)" ${ }^{\prime \prime 14}$.

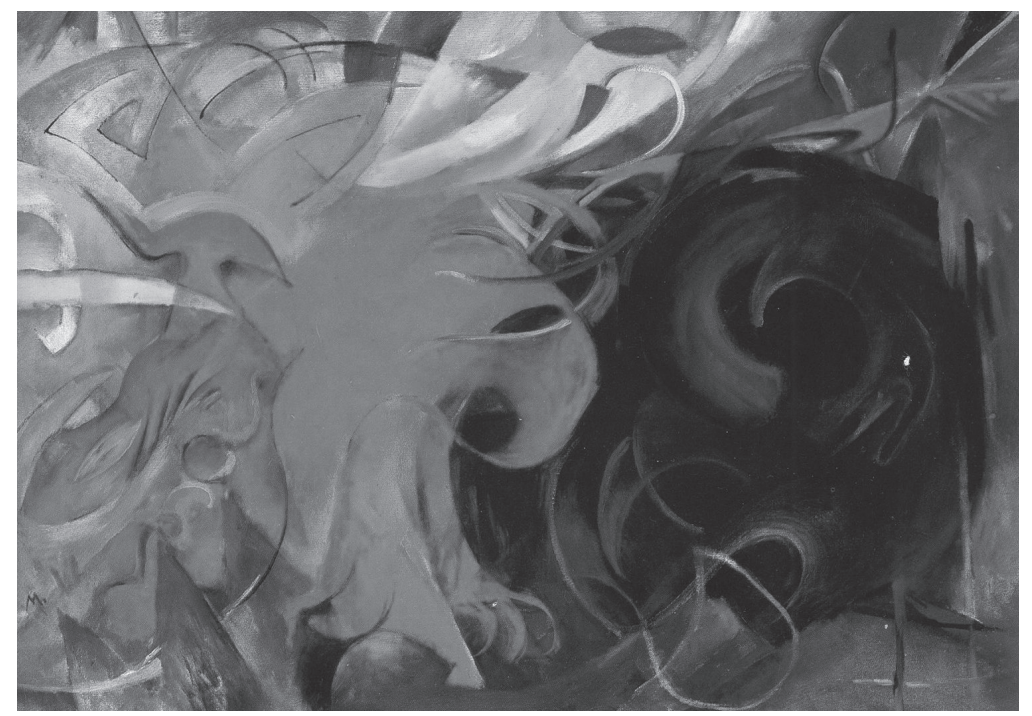

Franz Marc. Formas en lucha (1914)

Esta concepción "esquemática y abstracta" de la creación artística no era sino la reacción natural -y un tanto desesperada, a la verdad-contra la planificación política, industrial y científica propia del capitalismo burgués en la era de su expansión imperialista (de ahí los cantos agresivos al exotismo de los "pueblos sin estado" por parte de los artistas "degenerados"). Y es que, dentro de esta cosmovisión dizque tecnocientífica, el espacio no es ni ha sido nunca una aséptica condición ontológica de posibilidad de la matemática y de la física, sino también y ante todo condición de dominio: de los Kulturvölker sobre

\footnotetext{
${ }^{14}$ Franz Marc, Carta a Maria Marc de 12 de abril de 1915 (Briefe aus dem Feld Munich, Ed. Klaus Lankheit / Uwe Steffen, 1985, p. 65; subr. mío).
} 
los Naturvölker (y sus diversas y variopintas denominaciones eufimísticas); de dominio de unas potencias más "civilizatorias" - o sea, mejor dotadas por la industria de guerra- sobre otras; y en fin, dentro de esas mismas naciones esclarecidas, de dominio de unas clases y estratos sobre las capas más bajas de la población (y si no, atiéndase a la evolución y distribución de los espacios urbanos a partir sobre todo del siglo XIX).

Comparemos brevemente, a tal efecto, la moderna noción de espacio con la de los "espacios abiertos" en el mundo antiguo. Estos últimos presentaban una doble y antitética función: por un lado, agorá, forum o plaza del mercado (espacios urbanos cercados para la discusión, la administración o el comercio); por otro, el ejido (del latín exitum: lo que está "a la salida"): prados comunales situados extra muros para la explotación agropecuaria vecinal). Un doble movimiento, éste, de sístole y diástole de la ciudad: "polo de atracción" o puesta en común de los problemas del pueblo, y "exportación" del ámbito civilizado al territorio exterior, como anillo de transición -lo "cultivado" - entre lo salvaje -lo "inculto"- y el recinto o "cercado" (al. Zaun, de donde el ingl. Town) en que viene asegurada la "cultura", plasmada en un espacio de convivencia política, laboral y familiar.

Por el contrario, la también doble expresión geopolítica del Estado-Nación (sobre todo, a partir del Congreso de Viena, de 1814-15) es de un lado la capital centralizada, con la creación de grandes espacios abiertos, mediante la construcción de anchas avenidas y parques (piénsese en Washington, D.C., una ciudad de nueva planta, diseñada por Charles L'Enfant, con el National Mall entre las avenidas Constitution e Independence) o de grandes plazas (como La Concorde o L'Étoile, en París): todo ello, para las concentraciones y manifestaciones de un "público patriótico": un surtido de ciudadanos "producidos", fabricados y troquelados (con diferentes grados de calidad en el acabado, naturalmente) por la maquinaria burguesa estatal, junto con el espacio urbano correspondiente (el recipiente vacío para ser llenado por las masas enfervorizadas), con su "mobiliario" y sus "espacios verdes". Un espacio homogéneo y neutro que da la medida, a fin de acoger en su seno a la multitud de "átomos razonables" (externamente enlazados entre sí por fuerzas económicas y de formación de la opinión pública: dignas herederas de la harmonia praestabilita leibniziana), a la vez que ese mismo espacio público es mensurable, según los supremos intereses del Estado (el cual, a su vez, obedece también a los intereses privados de las mencionadas fuerzas, en un nunca bien acabado bucle de retroalimentación). Hoy, los antiguos ejidos (los suburbios) están tachonados -según la distancia a las grandes conurbaciones descentralizadas- de nudos de autopistas o de rotondas para la regulación del tráfico, mientras que las anti- 
guas plazas (piénsese p.e. en la Place des Vosges en París, o en la Puerta del Sol en Madrid) han sido remodeladas como lugares para el efímero desplazamiento de turistas, como refugio de desocupados o de las "clases" improductivas, o -de manera imprevista, y creciente- como puntos neurálgicos de protesta ciudadana: espacios que, de nuevo -aunque en ocasiones por motivos poco deseables para el Estado-, funcionan como neutros recipientes vacíos, a ser "llenados" por grupos heterogéneos y a las veces poco y mal avenidos. En cambio, la "realidad" político-económica tiene lugar hoy en espacios cerrados, y más: "blindados" e inaccesibles para el público (salvo en las llamadas "jornadas de puertas abiertas"). El sarcasmo es aquí patente: los "edificios públicos" han de ser protegidos por las "fuerzas de orden público" contra las protestas y reivindicaciones -cada vez más frecuentes- del público, como en el caso del español Congreso de los Diputados.

En suma, tras estas consideraciones, bien podemos aventurar una descripción del espacio como articulación planificada de lugares panorámicamente controlados, acompañada, en el caso del moderno espacio vacío de la geopolítica, por la "creación" simultánea de "átomos-ciudadanos" que, integrados molecularmente mal que bien, han sido predestinados para ocuparlo; esa masa confusa de átomos es denominada: público en general, un idealizado patriota, tan ejemplar como inexistente. Las deficiencias de esa articulación y de esa creación saltan, por demás, hoy a la vista. Y la tendencia no cesa de incrementarse.

En todo caso, esa ha sido -y seguirá siendo por un tiempo, por defectuoso que sea su funcionamiento- la quintaesencia de la modernidad, plasmada en la gran ciudad (la metrópolis o Weltstadt), a saber: que todo sea signo, y nada "natural" (esto último en el sentido, ya casi olvidado, de la physis aristotélica, claro está).

Hoy, el arte y el espacio -el arte del espacio- reflejan claramente esa degradación de aquello que, entre los esperanzados sixties y los felices nineties, fue calificado -de manera harto optimista-como arte público, y que ya en 1964 se encargó Martin Heidegger de "poner en su sitio"15. De tal declive no es sólo causante de ello la crisis económica de la mal llamada globalización, sino la irrupción -contemporánea a la crisis, en la primera década de este siglo XXI-

${ }^{15}$ En las Bemerkungen zu Kunst - Plastik - Raum (la conferencia de 1964 en honor de Bernhard Heiliger, que por entonces comenzaba a crear grandes esculturas abstractas de bronce para las calles y plazas de una Alemania en plena reconstrucción tras la guerra), alude Heidegger a la nueva función y situación de la plástica, la cual: "entra en una referencia inédita con el paisaje industrial, en coordinación con la arquitectura y el urbanismo. La plástica está llegando a ser, junto con otros factores, determinante para la planificación del espacio" (Erker, St. Gallen, 1996, p. 6). 
de la revolución informática, ${ }^{16}$ acompañada en las artes audio-visuales por el llamado iconic-turn, propiciado y propulsado a su vez por las ensoñaciones postmodernas y retro-New-Age de la llamada virtual reality: ese hiperkantismo que promete al usuario tener "el mundo en sus manos" (o mejor: en su datasuit) al hacer que el cuerpo (convenientemente computerizado) del sujeto se pasee por un entorno artificial replicante que "responde" a sus movimientos y acciones. Es evidente, sin embargo, que lo único de veras existente en este aparataje es la interfaz (el diálogo de máquinas entre estímulos -artificiales-y respuestas -inducidas-), donde toda interacción tiene lugar entre pulsiones neuronales revestidas con terminales y un mundo entorno digitalizado. No menos evidente es que, en esta exaltación del individuo encapsulado y del ciberespacio de su actuación -ambos artificiales, en todos los sentidos: también y sobre todo en el ideológico-, las manifestaciones de escultura urbana y de arte público obtengan cada vez menos favor por parte de la autoridad sedicentemente "pública". Para el entertainement ya se tienen los parques temáticos y los grandes casinos: simulacros a gran escala y correlatos lúdicos de los edificios cerrados de las empresas multinacionales y de la administración (supra)estatal. En este New Brave World, lo que queda en entredicho es justamente la función del arte como mediación ente la realidad y el ser humano. Aquí, todo brilla, sin centro ni foco: lux sine lumine. El espacio queda anulado, o mejor asumido en el hiperespacio de un cibertexto coextensivo ad limitem con la red informática planetaria. El tiempo es sarcásticamente considerado como "real", justo porque el archivo y registro de la imagen coincide con su aparición "ahora": un punto congelado. El nuevo nihilismo: Metafísica del presente... simulacral, y de la presencia... de nada.

Y sin embargo, no todo está perdido. De lo contrario, sería inexplicable la fascinación que despierta en muchos la obra de Chillida (y de Serra, de Oteiza o de Caro, por nombrar algunos de los escultores plásticos cercanos a él). Difícilmente podrá extirparse por entero esa fascinación, por una sencilla pero poderosa razón, a saber: seguimos siendo los únicos animales (las máquinas quedan de antemano descartadas) capaces por un lado de hacer abstracción de las percepciones sensibles para captar la forma ideal de unificación de las sensaciones; y ello, en diversos grados: desde las imágenes a los conceptos empíricos, de éstos a los conceptos puros o categorías, y de éstas en fin a las ideas.

\footnotetext{
${ }^{16}$ Igualmente cantada en los Sixties por R. Buckminster Fuller, el profeta de la "Second Revolution to the People": Informatics (1969), y mantenida a duras penas - tras el triunfo de la Mobile Age- por artículos como el de George Kesaria: Microsoft: In the Forefront of the PC Revolution Once Again. En: Seeking Alpha, 6 de noviembre de 2012 (seekingalpha.com/.../982631-microsoft-...).
} 
Todo ello muy lógico, muy kantiano... y bien conocido. Pero también somos capaces (la mayoría de las veces, a través de la obra artística) de abstraer lo puramente sensible que hay en esas percepciones, esto es: la materialidad de éstas, lo subyacente a toda forma y previo por ende a toda medida; podríamos llamar a eso la condición material de las cosas del mundo, y del mundo de las cosas. En la jerga de las artes plásticas suele llamarse al atributo de esa condición: lo matérico.

Ahora bien (y éste es el rasgo capital), esa materialidad no es en absoluto amorfa, ni invisible ni intangible ni inaudita: ¿cómo iba a poseer cualidades negativa cuando ella surge de una colaboración originaria entre los órganos sensoriales humanos, las características propias de los materiales, patentes a aquéllos, y los contextos generales? Por cierto, contextos, todos ellos, cálidamente agrupados en torno a una misma raíz idg. *tep: "calor" (de donde "tibio"), en lat. tepor, de donde tempestas (originalmente, las estaciones del año), temperies, temperamentum, temperatura (todos esos términos aluden a una combinación armónica y ajustada, en la debida proporción), y por fin el tiempo atmosférico y meteorológico, y el tiempo cronológico (la última y más exangüe de las abstracciones, a partir de la luz y el calor (o frío) del día y la noche, según las estaciones). Ahora sabemos, por lo demás (y aquí la ciencia y la sensación pura se dan la mano) que es el grado de temperatura el que decide de las características de la materia y, en última instancia, de la existencia misma de las cosas (la temperatura mínima absoluta es $0 \mathrm{~K}$ [elvin] $=-273,15^{\circ} \mathrm{C}$ [elsius]).

La estrecha copertenencia de temperamentum (en el sentido tradicional, hipocrático: equilibrada combinación de los humores en el cuerpo humano), de tempestas y de temperatura aluden, como he dicho anteriormente, a una colaboración, y más: a una cuasi identificación primigenia (presente también en la estrecha cercanía entre "sensación" y "sentimiento"), a saber: existe un umbral previo a la distinción entre sujeto y objeto, entre el hombre y las cosas (si queremos: entre el pensar-sensu lato-y el ser), que sólo puede ser entrevisto en la obra de arte: ella misma, el mejor ejemplo de contexto o conexión, de temperies que, a su vez, genera otros grupos subordinados de contextualizaciones, al igual que un símbolo (gr. sýmbolon, de sym-bállo, lo "lanzado conjuntamente") irradia y engendra signos derivados.

Ahora bien, esa protounidad, esa comunión íntima entre el hombre ${ }^{17} \mathrm{y}$ las $\operatorname{cosas}^{18}$, en suma: ese entrecruzamiento de conexiones y contextos, se dice de

${ }^{17}$ El término "hombre", del lat. homo, procede de humus: la mezcla orgánica y rica en nutrientes de la superficie de la tierra.

${ }^{18}$ El término "cosa", lat. causa, ingl. Thing, al. Ding, significaba originariamente: "reunión, asamblea", como cuando un grupo de guerreros se senstaba en torno a un fuego para dirimir a 
varias maneras, todas ellas dependientes en definitiva del calor y del frio (¿cabría acaso dudarlo, tras el examen que hemos hecho de tempus/tepor y de su campo semántico?). Pues bien, la concreción primera, la materialización liminar de esa textura primigenia se nos muestra como los diferentes estados de la materia (según la gradación de temperatura, de lo frío a lo cálido): lo sólido o lo fluido, lo denso o lo rarificado, percibido por el ser humano en virtud del primer y más importante órgano temorreceptor: la piel, específicamente irritable en las zonas en que con mayor fuerza se manifiesta el sentido del tacto: en las manos, por las cuales entramos en contacto con las cosas y podemos manipularlas. De ahí también la generalización (fundamental para las artes plásticas contemporáneas) entre lo lleno y lo vacío, la materia y el espacio.

Por otra parte, la irradiación del calor se presenta como luz (o su falta, como oscuridad, hasta llegar al "cuerpo negro"): de ahí la primera sensación de distancia entre la cosa (reducida entonces fundamentalmente a figura y perfil) y la vista (por cierto, también aquí el lenguaje nos avisa de la primordial equiparación -a través de la luz- entre la cosa distante y el órgano sensorial, ya que hablamos quiasmáticamente de la cosa vista y de la vista de la cosa, de tener una visión (de algo externo) y del órgano de la visión (algo interno).

Por último, la distancia visual y el contacto entre la piel y la superficie de los cuerpos viene mediado, sea por la resonancia (paradójica presencia inmediata de la distancia, mediante el sonido, recogido en la audición: lo oído y el oído, la audición y la fonación), sea por la dispersión de un fluido a través de un medio menos denso (el olor y el oler) o por la ingesta de sólidos o líquidos diluibles (los alimentos y la boca).

Repárese en que, en todos estos casos, con excepción de la ingesta de alimentos ${ }^{19}$, existe un umbral de indistinción relativa entre el humano "ponerse a distancia", guardando los "respectos" (de ahí la voz derivada: "respeto"), por un lado, y lo que podríamos llamar: "el salir los objetos (en alemán:

quién le correspondía una parte del ganado botín (recuérdese la ira de Aquiles con que comienza la Ilíada). Todavía hay un rescoldo de esa idea de reunión, pero también de litigio, cuando decimos que hay que luchar por una buena causa, o cuando sa habla de una causa judicial y de los encausados. También en las "cosas", en la acepción -más abstracta, y a la vez más cotidiana- de las situaciones o los asuntos (las "cosas de la vida"), resuena todavía esa idea de contexto situacional (casi podríamos decir: de temperie o de intemperie, en aplicación a la "atmósfera" espiritual de una persona).

${ }^{19}$ La alimentación supone la colaboración más inmediata y, para algunos espíritus selectos, grosera (puesto que interioriza lo exterior, más allá del mero contacto, y además entraña una ulterior defecación) entre la materialidad de lo terrestre y los órganos sensoriales; de ahí que haya sido la última también en haber sido elevada en algunas ocasiones a obra de arte (ciertamente efímera), como en el arte culinario de grandes chefs como Ferran Adrià, con El Bulli y su combinación de texturas, aromas, colores, etc. 
Gegenstände) al encuentro", por otro: una acción compleja, de entrega y eclosión, muy bien formulada por el término alemán: Begegnung, en donde resuena la raíz gegen (al igual que en Gegenstand: "objeto"), con el sentido dialéctico de "ir hacia" y "venir en contra": la conjunción o entramado -el paisaje humano y natural- de este salir los objetos hacia/contra los sentidos del hombre da origen a la Gegend, la "co-marca": el nexo de los encuentros ${ }^{20}$.

Esta difícil mediación (poner a distancia: dejar ver u oír los respectos o relaciones de las cosas en su perfil, silueta o radiación) de la inmediación (tocar, palpar, oler y gustar algo por delegación, a distancia, de manera transfigurada) se fragua y forja en la obra de arte. Y el arte en el que todo ello viene devuelto al sentido primordial del tacto es la escultura plástica: allá donde se promete y anticipa, a través de la visión, el contacto entre la piel del hombre -especialmente, sus manos- y la trabajada y bien labrada superficie de los cuerpos. El contraste, en este punto, con la escultura en el sentido tradicional, es evidente. La estatuaria supone la idealización del cuerpo, alejado de todo contacto (al extremo, porque la imagen representa algo divino, algo que debe estar separado del mundo profano para servir de inalcanzable modelo en él). Por el contrario, la plástica le saca por así decir los colores, las texturas, el calor, la vibración o la posición a las formaciones materiales (a las conformaciones de materiales) que ya no necesitan parecerse a cuerpos, sean éstos divinos o humanos. Al contrario, son ahora los cuerpos humanos los que se acercan, púdicamente al principio, dando vueltas en torno al volumen y a los espacios de la obra, buscando a tientas un nuevo e inédito contacto con la bien temperada piel de la tierra.

Seguramente ha sido Johann Wolfgang Goethe el que con mayor precisión y elegancia haya formulado esta tarea del arte ${ }^{21}$ como colaboración primigenia del hombre y la naturaleza, y más: como interacción y hasta recíproca transfiguración o transmaterialización entre el sentir y lo sentido: la glorificación del fenómeno (de phainómenon: la "aparición", eso que se da a ver, que se muestra) en cuanto tal. Como es difícil (y al extremo, imposible) hacer justicia al denso texto en que Goethe presenta su teoría en el sentido casi olvidado de la voz griega: theoría ("arte de saber ver") iré comentando al pie los diversos ver-

\footnotetext{
${ }^{20}$ En castellano se pierde un tanto este primordial: "salir al encuentro"; no así en otros idiomas europeos, como ingl. country, francés contrée o catalán contrada: la habitación de los hombres como siendo-en-el-mundo.

${ }^{21}$ Una formulación propia del Naturforscher, por lo que hay que tomar "arte", aquí, en el sentido más amplio de "indagación de la naturaleza". La concepción de Goethe supone, por cierto, un abierto contraste y oposición respecto de las corrientes contrapuestas de su época (y no sólo de la suya): empiristas, sensualistas y materialistas, por un lado, e idealistas, racionalistas y espiritualistas, por otro.
} 
bos por utilizados por el poeta-científico: "Todo acto de mirar (Jedes Ansehen $^{22}$ ) se torna en un considerar (geht über in ein Betrachten ${ }^{23}$ ), cada consideración en una donación de sentido (jedes Betrachten in ein Sinnen ${ }^{24}$ ), cada acto de dar sentido a algo se torna en un conectar (jedes Sinnen in ein

${ }^{22}$ Una versión pegada a la letra del verbo ansehen sería "ver a" (alguien o algo); pero también se utiliza para indicar que algo es tomado por algo (o sea, que es identificado como siendo tal o cual cosa), o, desde el lado subjetivo, implica un presenciar, un ser testigo de algo. El sustantivo derivado Ansicht sería "manera o modo de ver" las cosas; y de ahí, "opinión", "convicción", etc. Aquí, como indica el prefijo an-, lo importante es la cosa; pero al ser ésta vista, mirada o contemplada, queda entonces revestida de un significado subjetivo; de ahí que ansehen o Ansicht constituyan por así decir el grado inferior de la comprensión o interprtación de la realidad. Cf. la novela de Heinrich Böll: Ansichten eines Clowns (1963), traducida en español como Opiniones de un payaso (Barcelona, Seix Barral, 2001).

${ }^{23}$ Puede decirse que betrachten designa un movimiento inverso a ansehen. El prefijo beimplica dirección (al igual que an), pero enfatizando aquí al sujeto que se dirige hacia algo (el prefijo convierte al verbo en transitivo, y al sustantivo mentado en complemento directo u "objeto"); el verbo trachten proviene de la misma raíz que el latín tractare, de donde también trahor, "tirar hacia uno", como en "tractor", presente además en "tratado" (libro científicamente articulado) y en "tratados" o "contratos". El verbo betrachten suele traducirse -correctamente- como "considerar" o "tomar en consideración", es decirse: "pararse a pensar" (bedenken, sinónimo de betrachten) o "reflexionar" en el sentido de algo, y en las ventajas o perjuicios que la cosa considerada tiene para el sujeto. Pues, aunque la raíz de consideratio es bien distinta a betrachten, sin embargo guarda una curiosa y recóndita semejanza con lo mentado en alemán; la raíz remite al latín sidus: un astro o una constelación, de ahí "sideral"; el prefijo enfatiza la idea de "contexto" (o justamente, de constelación); en suma, originalmente la consideratio era la interpretación conjetural de una existencia a partir de la conjugación o constelación de los sidera, de los astros en el momento del nacimiento, para "tomar en consideración" a partir de ello la suerte (mala o buena) del neonato. La consideratio seguramente más famosa en el teatro español es la prescrita a a Segismundo en el momento de nacer, y realizada a instancias de su padre Basilio, Rey de Polonia, en $L a$ vida es sueño, de Calderón (el antecedente griego, más alto, es naturalmente el Edipo Rey, de Sófocles).

${ }^{24}$ Una traducción cabal de sinnen es punto menos que imposible. El verbo puede significar a la vez (y en Goethe sucede así) "recapacitar, cavilar, meditar" (sinónimo de nachdenken: "volver a pensar" en algo) o, como sinnen auf: "aspirar, encimnarse a algo" (sinónimo de trachten; recuérdese que Goethe está equiparando aquí Betrachten y Sinnen). Además, etimológicamente, sinnen remite a Sinn: "sentido" (cf. "sendero", de la misma raíz), en cuanto "significado en movimiento" (cf. el sentido de una palabra, pero también una vía de doble sentido), y de ahí, figuradamente, pasa sinnen a significar "ser sensato", saber sopesar los pros y contras de las cosas (pero también: "tener buen ojo"). Por otro lado, Sinn (sobre todo en plural: Sinnen) es un "sentido": como la vista o el tacto. La sustantivación de sinnen es Besinnung: "meditar las cosas con vista y con tacto". Heidegger utiliza el sustantivo para oponer su "pensar meditativo" al "método científico"; cf. Wissenschaft und Besinnung, en esp.: "Ciencia y meditación" (en la recopilación, ya citada, Conferencias y artículos).- En el texto de Goethe, he vertido Sinnen por "donación de sentido" en el doble sentido de que nosotros, los hombres, damos sentido a las cosas (y así, en ese "sentido", nos ponemos en camino hacia ellas, como en la Sinngebung husserliana); pero lo hacemos porque, a su vez, las cosas nos incitan, al marcarnos el sentido por el que debemos encaminarnos (la "senda" que podamos tomar, en vista de la situación y las circunstancias; recuérdese la pregunta que, en un sueño, marcó la trayectoria vital de Descartes: quid vitae sectabor iter?, "¿qué camino seguiré en la vida?"). 
Verknüpfen ${ }^{25}$ ); y así, bien puede decirse que nosotros, en cada mirada atenta al mundo, estamos ya teorizando (und so kann man sagen, dass wir schon bei jedem aufmerksamen Blick in die Welt theoretisieren ${ }^{26}$." ${ }^{27}$

Si me he demorado de manera tan prolija en el examen del texto de Goethe es porque considero que brinda un espléndido epitome de la entera obra de Eduardo Chillida, el cual no en vano dedicó al poeta-científico una de sus creaciones más hermosas: la "Casa de Goethe"; o mejor, para él: Ein Haus für Goethe (1982-1986), ubicada en el Taunusanlage de Francfort del Meno (se trata de un armonioso parquecillo, sitiado por los rascacielos de las grandes Firmen y Konzernen de la capital económica de Europa).

\footnotetext{
${ }^{25}$ En filosofía, este verbo sustantivado trae enseguida a la mente la distinción kantiana entre Zusammensetzen (compositio: aggregatio sive coalitio) y Verknüpfen (nexus), como especies del género Verbinden ("enlazar, combinar"), que designa la función de enlace (o separación) entre el sujeto y el predicado oculta en el juicio; mientras que "componer" es una vinculación externa entre cantidades homogéneas (y por eso conviene a los juicios "matemáticos"), "conectar" implica una síntesis heterogénea entre el sujeto (una intuición) y el predicado (un conepto): corresponde a los juicios "dinámicos"; en ellos se denota algo existente, como la relación de sustancialidad o de causalidad, o, en los juicios de modalidad, el modo en que el sujeto cognoscente (ya no meramente el sujeto de la proposición) enjuicia, "toma en consideración" el modo en que se le presenta a él la cosa juzgada: como algo que puede existir, que de hecho existe, o que existe necesariamente (cf. Crítica de la razón pura B 201, nota).- Obviamente, este sentido de "modalidad", en la que el cognoscente y lo conocido, el sujeto y el objeto (dos magnitudes heterogéneas) entran en mutuo contacto, es lo que más podía interesar a Goethe de la "meditación" kantiana.

${ }^{26}$ Podríamos decir, con una punta de exageración, que Goethe, en suma, está retraduciendo el neologismo theoretisieren al griego de origen (theoréin, theoría), al definirlo tácitamente como aufmerksamen Blick in die Welt; el adjetivo remite a merken auf, "parar mientes en" algo; literalmente, "marcarlo" (merken) al "echarse sobre (auf) ello"; el sustantivo indica una clara actividad subjetiva: Blick remite a Blitz, el rayo o fuego que sale de los ojos y "colorea" y da sentido al objeto considerado; y por fin, el acusativo direccional puede ser interpretado (en un sentido que va más allá seguramente de las intenciones de Goethe) como "iluminar, echar luz sobre el mundo" (o sea, el contexto o conexión total; el ser-en-el-mundo heideggeriano). Ahora bien, repárese al fin en que, aunque la actividad del sujeto (mutatis mutandis, la del artista) sobre la materia es la predominante (la composición formal prima sobre la mera materialidad de los elementos), la "mirada atenta" es posible porque ella recoge dentro de sí todas las incitaciones procedentes de las "cosas" o lugares-situaciones térreas o matéricas, de manera que la tarea del artista o creador (pero atiéndase al plural empleado: wir, "nosotros") es devolver a las cosas, mediante una reconstrucción atenta en palabra y obra, la verdad esencial de las mismas: una verdad que en su aparición mostrenca ellas ocultaban, e ignorada por los hombres en su vida cotidiana (cf. la Elegía IX de Duino, de R.M. Rilke).

${ }^{27}$ J.W. Goethe, «Zur Farbenlehre. Didaktischer Teil. Vorwort», en Naturwissenschaftliche Schriften, Munich, C.H. Beck, 2002, p.13 y 317.
} 


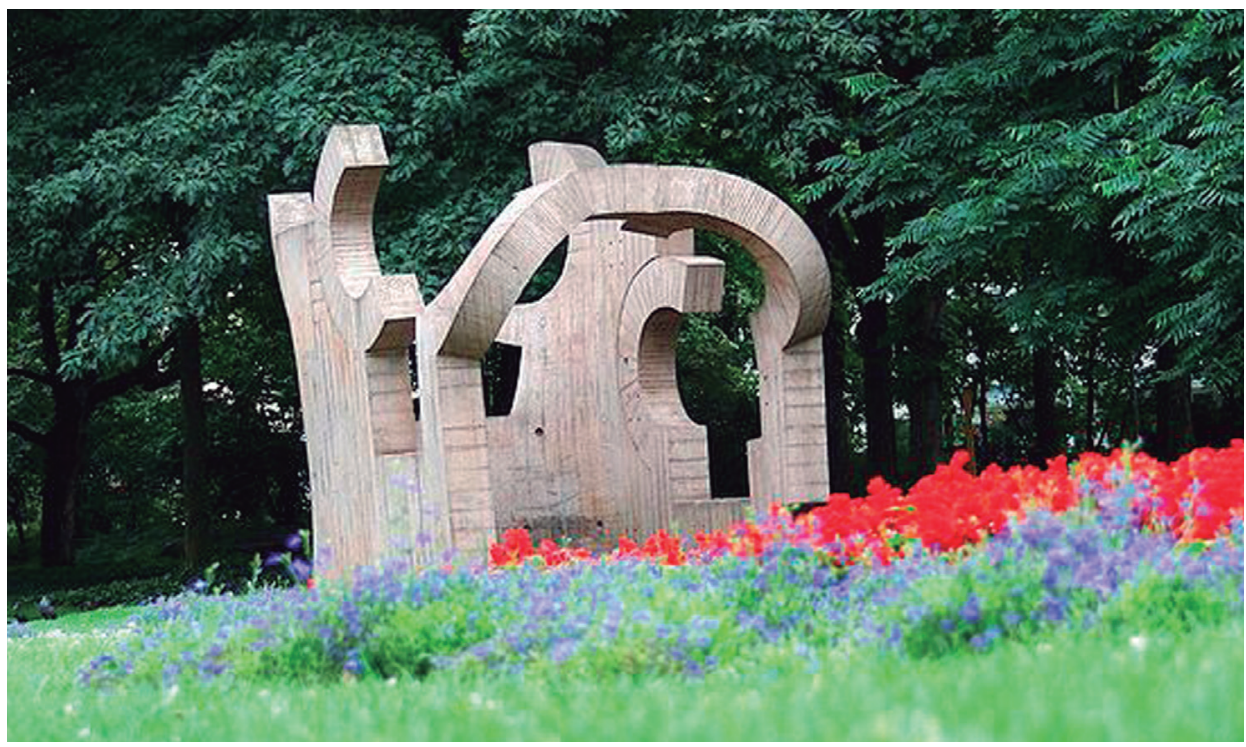

Una casa para Goethe (Frankfurt/M)

Por cierto, las palabras del poeta describen con rara perfección avant l'oeuvre el quehacer del escultor vasco es algo que puede venir corroborado por la sentencia, lapidaria y hermosa en su concisión, de otro gran poeta, Yves Bonnefoy, el cual sostiene que en las obras de Chillida se da una "identidad absoluta entre su apariencia y su esencia" (identité absolue entre leur apporence et leur essence). ${ }^{28}$

Y eso es lo que nos dice, en efecto, la constelación de las obras de Chillida: que la verdad no está ni en el concepto lógico o la fórmula matemática (aunque sin ambos sería imposible el basamento técnico que exige la complejidad de la obra plástica) ni tampoco en la percepción sensible, espacio-temporal, de esa extraña "cosa" de hormigón, de hierro o de granito que está ahí, sino en la interacción directa, sensorial, intuitiva del hombre en cuanto ser-en-el-mundo, y del mundo en cuanto el estar-del-hombre. Ese quiasmo dice: habitación de tierra. Tal es la alta tarea del artista: restituir la presencia misma de la tierra y sus materiales, ocultos como están bajo el imperio del signo y de la manipulación tecnocientífica. Se trata, en definitiva, de la destrucción metódica de la representación, y de la transfiguración de lo en ella esenciado (en cuanto ínti-

${ }^{28}$ Bonnefoy, Y., «Eduardo Chillida», en Chillida, París, Galerie Lelong, 1990, p. 25; cit. En el excelente estudio de Patricia Martínez García «Yves Bonnefoy face à Eduardo Chillida: poétiques de l'objet sensible», en Revista de Filología Francesa n ${ }^{\circ} 8$ (1995), UCM, Madrid, 83-99; aquí, p. 97. 
mamente desplegado) en la presencia de la cosa, presente a su vez en su composición esencial a la mirada del artista, o mejor: del technites, en el sentido griego del término.

Se da aquí una presencia viva, más que de lo natural, de la tierra misma, compareciente en la vivacidad magnífica de los materiales: hierro, alabastro, madera, piedra, chamota. De la tierra, en su relación con la formación plástica de conexiones inéditas; colaboración, o mejor: compenetración de la materialidad trabaja$d a$, formada, y de la configuración que pone de relieve tanto los materiales como su irse al fondo; dos movimientos contra-puestos ad intra y a la vez ex-puestos ad extra -en su concreta plasmación- a la luz y a la intemperie, a la formositas de sus perfiles y oquedades, pero también a la lenta erosión de los materiales. La obra no está nunca acabada: ha de contar con la luz y la lluvia, con el frío y el calor, mas también con los cuerpos vivos de quienes transitan entre las obras (estoy pensando sobre todo, claro está, en la Anlage o instalaciones-parque de Chillida Leku, en Zabalaga). Con una matización, respecto de las palabras de Goethe: aquí se da, ciertamente, una intensa interacción entre el componente físico y el saber-hacer (como la sophía griega) de la mano hábil y la mirada atenta, que confiere conformación y configuración a los materiales, al ponerlos en obra. Pero, en Chillida, esta configuración o Gestalt está al servicio de la materialidad misma y de su juego de reciprocidades, de conexiones, remisiones y diferencias, en un sabio juego de trasiego de cualidades y texturas, de escorzos y perfiles, de brillos y penumbra, como en una suerte de inédita sinestesia objetiva.

Estamos lejos de todo acto de servicio, lejos incluso de la última tentación: la del artista creador que estimara, presuntuoso, que la obra no sería sino la expresión de su espíritu. En este estricto sentido, no hay nada de romanticismo en la obra de Chillida. Y si no, contémplese (aquí, el pensamiento se quedaría muy corto) la Estela IX de Lo profundo es el aire (1989), en un prado de Zabalaga; y diríjase la atenta mirada con tino (recuérdese el Sinnen goetheano) a la interacción que se da en la obra entre la rugosidad del granito, la usura de la piedra desollada, erosionada, como una columna truncada, versus la geometría de los mentidos ángulos rectos (por lo común, oscilantes entre ángulos de $85^{\circ}$ a $87^{\circ}$, y de $93^{\circ}$ a $95^{\circ}$ ): las aristas de la piedra pulida que conforman un espacio arquitectónico, emergente a su justo tiempo (tempo, también, en sentido musical) en el corazón mismo de esa materia. O como señala con precisión poética Patricia Martínez: se trata de "dejar aflorar la traza del tiempo en el seno mismo de la geometría de los números. ${ }^{29} \mathrm{O}$ dicho de otro modo: se trata de impedir que la forma se separe de la realidad sensorialmente sentida, para acabar por sustituirla.

${ }^{29}$ Martínez, P., op. cit., p. 92. 
Nada de figura ni de imagen. Pero tampoco abstracción. Si acaso, ex-tracción: traer a la luz y la mirada lo profundo en cuanto profundo (recuérdese el Betrachten goetheano). De ahí que, frente al hiperbólico rigor del llamado "arte abstracto", las obras, o mejor: las series - experimentadas y experimentales- de Chillida conserven siempre un resto de figuración, como un tierno y a la vez sobrio homenaje a las formas más simples y rudimentarias del entorno sensible: los ritmos y los movimientos elementales de un mundo puesto en obra. Bien conviene entonces a la jovial serialidad chillidiana la confesión -no menos sobria y concisa, exacta en su simplicidadde Paul Klee: "El arte no devuelve lo visible, sino que el arte hace visible." (Kunst gibt nicht das Sichtbare wieder, sondern Kunst macht sichtbar) ${ }^{30}$. Ahora, todo depende de evitar la tentación mística, prolongando así la frase: "hace visible lo invisible". Pero no hay tal: el arte hace que lo visible lo sea de verdad: deja ser a lo visible en cuanto tal, oculto sin embargo a la vista, al tacto y al oído por los prejuicios del habla cotidiana, de los oficios varios y de la política discutidora.

Lo visible no es la cosa, si por tal entendemos algo macizo, bien perfilado, volumétrico y, en suma, individual o, al límite -como gustan tantos de caracterizar la obra de arte- algo único (con lo cual alcanzará un alto precio en el mercado, al igual que un sello de correos borroso o con algún otro defecto: que hasta el carácter único de la falta tiene precio en un modo de repetibilidades mostrencas). En este sentido, Chillida se encontRaría en las antípodas de un Marcel Duchamp que se tomara a sí mismo en serio (o fuera tomado así por los demás), como cuando éste -en un acto subversivo sin precedentes- desengancha un mingitorio del gran sistema técnico (por decirlo con Niklas Luhmann) que lo da sentido y función, y lo presenta aislado y firmado, como La fontaine de vie (1917).

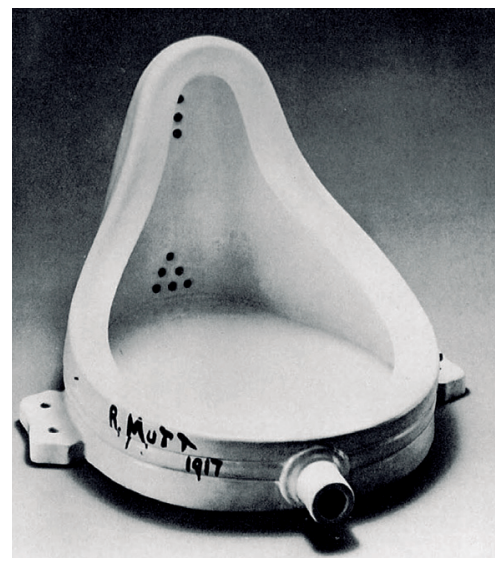

${ }^{30}$ Schöpferische Konfession (1920): «Übersicht und Orientierung auf dem Gebiet der bildnerischen Mittel und ihre raümliche Orientierung», en Das bildnerische Denken. Schriften zur Form- und Gestaltungslehre, Basilea/Stuttgart, Hg. v. J. Spiller. Benno Schwabe, 1956, p. 76. 
Como si la obra artística alcanzara carácter sagrado (Noli me tangere) al hacerse autosuficiente en su espléndido aislamiento. O llevando a su extremo esta idea, como si la obra no fuera ya el receptáculo, sino el producto mismo escatológico: enlatado, ciertamente, pero también firmado: cosa única para un artista único; unicidad irónicamente desmentida al disponer Piero Manzoni 90 latas de Merde d'artiste (si es que en realidad contenían tal cosa, ya que la apertura de la lata significaría el final del misterio... y de la artisticidad de la obra).

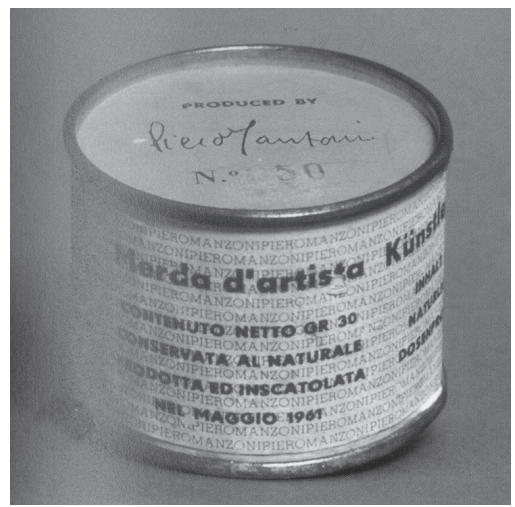

Piero Manzoni - Merde d'artiste

No. Lo que se da en Chillida (pues que de una donación se trata; una donación que no procede únicamente de él) es la intensificación, no la distorsión de las apariencias reales en su pura apariencia (en su gloria, según reza el término latino para el "aparecer": splendor entis). Hay aquí, por decirlo con Bonnefoy, una suerte de travail négat if contra el exceso de racionalidad, propio de las vanguardias modernas (contra lo que el hombre cotidiano -todos nosotros, a veces- pueda creer). Una suerte de pudor, de ascética castidad, a la escucha de las incitaciones de la materia por darse a conocer, por lucir y lucirse. En la obra no se dona una "cosa nueva", sino una nueva manera (maniera, de "mano") de nuestra relación con el mundo.

Y ello, con la máxima escrupulosidad técnica de base. De ahí la ambigüedad de los homenajes de Chillida, como en la mesa ingrávida de Zabalaga, dedicada a Luca Pacioli, el humanista que exaltara, con rigor ejemplar, el número áureo en su De divina proportione (1496-1498); el fictor del platonismo ficiniano, fascinado por las relaciones pitagóricas yh por la exactitud paadigmática de los sólidos regulares.

No. La obra de Chillida no representa ni designa una realidad (y menos, la realidad suprasensible de los paradeígmata platónicos), sino que, por un lado, es parte de la realidad de este nuestro mundo sensible, mientras que por otro 
hace participar a este mismo mundo en el contexto (mundus, kósmos) en que esa realidad tiene sentido en sí, o sea: para nosotros. La obra está dentro y fuera del mundo, como los vacíos en ella entrometidos. Propicia la aparición de mundo y a la vez está en el mundo (como en la diferencia ontológica entre el ser y el ente, avizorada por Heidegger).

De ahí su paradójico rigor flexible. En sus trazos se ofrece en efecto un rigor, bien temperado (como en el cémbalo de Bach) por la acción del ojo y la mano del hombre y a la vez y en el mismo sentido por la rugosidad de la tierra. Chillida no cree en el ángulo recto, pero se acerca, pudoroso, a esos límites en los que la rectitud rumorea. No cree en los sólidos regulares, pero se acerca al escetismo de su regula. No cree en los colores impuestos: pero en la simplicidad de sus series les saca los colores a los materiales con los que Chillida colabora, ruborizados en su nuda exposición. En una palabra, pudor: comunión con la tierra (expuesta en sus materiales) y el mundo (que cuenta una historia humana: la historia del hombre Chillida y de su pueblo). Pudor, en suma, porque tanto el artista como el contemplador aislado "están de más", de sobra.

Simplicidad: depuración de los excedentes, de los excesos retóricos de la imagen, de toda imagen y de toda imaginación. Despojo, expolio del cuerpo de la obra de todo desarrollo superfluo y toda tentación ornamental: despachando vacío en verdad. Fusión, tansfusión cordial de la mano y la mirada. ${ }^{31}$ Equidistancia del "idealismo" latente en la mímesis clásica y del reduccionismo abstracto de la geometrización radical de los purismos. Hacer visibles los derechos de lo sensible en cuanto sensibilidad.

Y es que el mundo está, desde luego, en la obra humana; pero lo está de esquiva manera: como soporte de la obra (como subyacente entramado de relaciones: mensurabilidad espacio-temporal de los relata, que se desborda por los márgenes: es la complexión de límites, perfiles y cortaduras que da ser y sentido a la obra: das Wesende); el mundo en obra, el mundo de la obra no funciona como un "mundo" externo (o sea, como algo trascendente a la obra, y cuya huella o copia se hubiera dejado "atrapar" dentro de los límites y volumen de la obra).

Y es que la obra, a su vez, está en el mundo, mas lo está de cuerpo latente, como mundo (o sea, como una "cosa" situada en un lugar del espacio y que dura un cierto tiempo), no como obra (o sea, como un contenido sedicentemente espiritual - producto del creador- que habría de ser recibido e interpretado por otro espíritu: el espectador o contemplador).

\footnotetext{
${ }^{31}$ Ver mi ensayo «La mirada y la mano», una introducción a las dos conferencias de Heidegger en la Galería Erker, de St. Gallen (cit. supra, nota 12), pp. 13-58.
} 
Llamamos arte a esa conjunción de inversiones. Cada término está literalmente fuera de sí, traspasado, volcado al otro. La obra que deja ser a mundo es el mundo en obra, el mundo que hay (se da, es gibt) en la obra. Sólo así, quiasmáticamente, está en $\underline{s u}$ lugar y crea sitio (cf. el site specific art $t^{32}$ ).

Ahora bien, esta consideración crucial es todavía demasiado estática y unilateral. Tal parece que mundo y obra fueran un tejido de relaciones o espaciales o bien algo que "está ahí". Sin embargo, ni el uno ni la otra existirían ni tendrían sentido si no contasen una historia, es decir, si no se dieran a tiempo y en dos movimientos igualmente antitéticos y quiasmáticos: pues que aquello que "se da a tiempo" resulta de dos factores (como si de un rompeolas se tratase): lo que se "echa encima", amenazador (uno de los sentidos de instans): el contratiempo, y lo que nos inserta en una instancia superior (el otro sentido de instans: lo que "insta" a hacer tal o cual cosa, como la Sombra del Padre de Hamlet le insta a tomar venganza del crimen): el redrotiempo. ${ }^{33}$

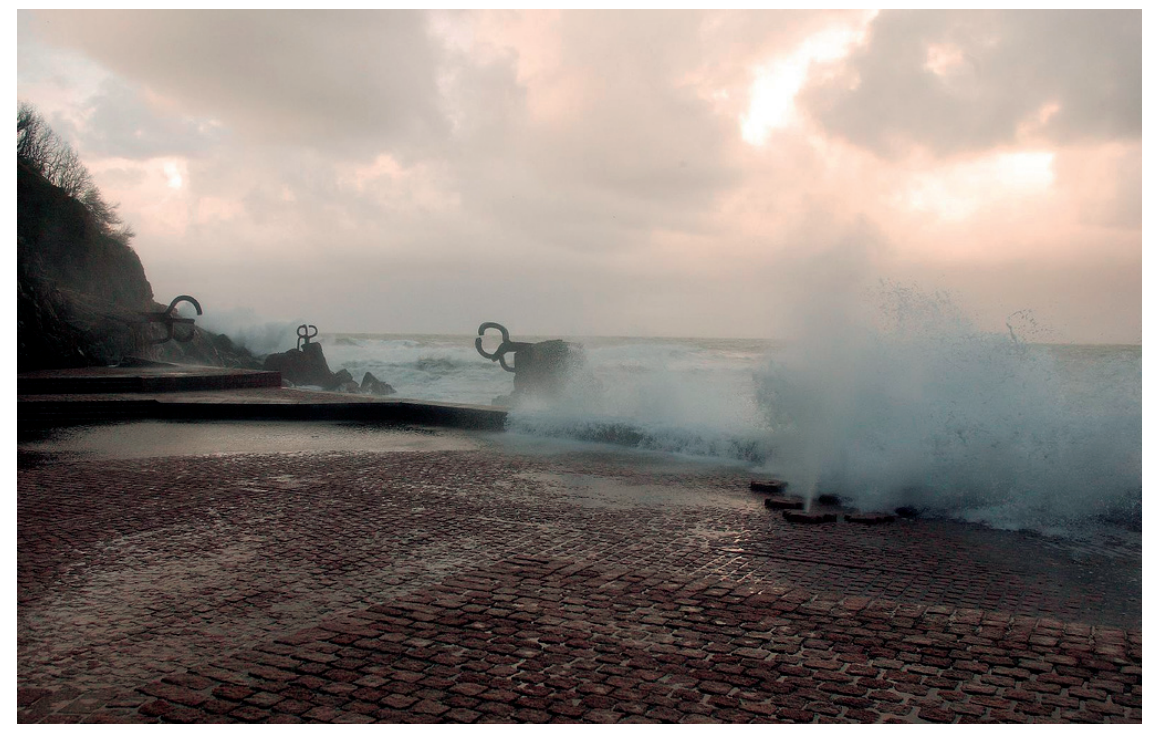

Chillida. El peine del Viento (San Sebastián)

\footnotetext{
${ }^{32} \mathrm{Al}$ respecto, remito a mi ensayo: «¿Es el arte del sitio el sitio del arte?», en De Llano, P. (ed.), Wrong site. Arte y globalización, A Coruña, Fundación Luis Seoane, 2008, pp. 152-181.

${ }^{33}$ Es el "desnacer" unamuniano: la (imposible) vuelta de las aguas a su fuente, como en el diálogo de Joaquín Monegro con Abel Sánchez, en la nivola homónima, o en el epitafio de Don Miguel en el cementerio de Salamanca: "Méteme, Padre eterno, en tu pecho / misterioso hogar. / Dormiré allí, pues vengo deshecho / del duro bregar." (procedente del Salmo III, vv. 5607; en Poesía completa (ed. de A. Suárez Miramón, Madrid, Alianza, 1987; I; 115).
} 
Esos movimientos contrapuestos vienen propiciados por el enraizamiento de los hombres en una tierra, en la que se honra a los muertos (no en vano se concreta la obra de Chillida en estelas, cipos, pequeños hipogeos de alabastro, cenotafios invertidos (como en el vaciado: kénosis, de Tindaya, todavía no realizado) y en las lurras (como si de urnas funerarias se tratase: terra arsa, la chamota añadida a la arcilla). Mas la obra del artista honra también esa tierra por venir: la tierra propiciada, instada por la apertura de espacios de convivencia para los venideros. Misiones y remisiones de tiempos retenidos y protendidos, de memorias y expectativas. Es en ese doble entrecruzamiento del contratiempo y el redrotiempo donde las cosas, las humildes cosas en que se forjan los quehaceres y afanes de los hombres, son llamadas por la obra a salvación o a redención. Ése es el mundo histórico de un pueblo: no una esencia siempre latente, que nos instara a sacrificarnos en todo caso por ella, de acuerdo con tradiciones ancestrales: tal es el esencialismo, plasmado a las veces en nacionalismos irredentos, y que acaba por enquistarse, como un cáncer, en el alma de los hombres, soñando con la nación al fin libre, pero con fronteras, para delimitar su lugar natural. También él, el lugar, inmóvil como sede de la Nación una e indivisible: la sagrada unidad de la Patria. No. Al igual que en la biografía del individuo, aquello que literalmente se le echa encima, aquello que le ocurre, es lo que le hace rememorar (como en un momento de peligro) aquella situación, aquel redrotiempo en el que él mismo, ahora, se reconoce... cuando ya es demasiado tarde para ser, sin más, aquello que supuestamente él ya era, mas también demasiado pronto para dejarse ir, sin más, por aquello con lo que él se encuentra: el contra-tiempo. En ese rompeolas del instante, sólo cabe la acción creadora, retroferente y proyectiva, a la vez. Ser otro a cada instante, recogiendo el pasado que urge a hacer algo, avizorando el futuro que incita a dar coherencia, dirección y sentido a la acción. Que no hay determinación (el continuum de la sucesión temporal) sino en la indeterminación (el ahora de cada marca de tiempo).

Si esto es así, entonces el mundo histórico no es desde luego algo dado (el "Hogar de nuestros padres" no es Euskal Herria; pero sin esa obra y su brecha, el sentimiento de "la tierra vasca" podría ser manipulado en favor de la "sangre y la tierra" de los ancestros: tampoco les promete a los vascos un vasto caserío de acogida ni les ofrece un paisaje prêt-à-porter); y menos aún se merece el mundo histórico ser celebrado en una mera exaltación hagiográfica del pasado como protección del presente: algo así como una montaña sagrada sobre la cual se asentaran individuos o pueblos, agradecidos por ser el resultado de una herencia (recuérdese que Chillida, como James Turrell, quería vaciar una montaña para - de profundis-ver desde ella el cielo, no para alzarse en su 
cima como lugarteniente de Dios y dominar desde esa posición el territorio a los pies $^{34}$ ).

Por el otro extremo, tampoco es el mundo una progresiva y siempre frustrante separación de un pasado que se hace indeseable e inservible a cada golpe de tiempo-ahora, defectuoso y viejo: siempre al servicio de un futuro (digamos: la Humanidad unificada, cosmopolita) al que sacrificar la propia savia del presente. No. Un vasco de origen proyectado en el futuro, un español encarnado en el pasado; en suma, un poeta, un poietés como Gabriel Celaya niega, al igual que Eduardo Chillida, tanto la turbia ensoñación romántica como la demasiado clara (y ofuscante) creencia moderna en el progreso.

No reniego de mi origen,

pero digo que seremos

mucho más que lo sabido, los factores de un comienzo.

Españoles con futuro

y españoles que, por serlo,

aunque encarnan lo pasado no pueden darlo por bueno.

Sólo así, en este cruce difícil de libertades que, porque ya no son, todavía pueden ser... siempre de otra manera, es donde un pueblo puede conectar sucesos con eventos, proyectos con trazas, misiones con remisiones. Ese conjunto de conexiones (ya lo vimos antes, con la Verknüpfung de Goethe) es, justamente, un contexto móvil, vivo y cambiante. El mundo-historia, el mundo-a-tiempo, no se va haciendo y deshaciendo porque nosotros estemos en un mundo, sino porque nuestro ser consiste en ser-en-el-mundo cuidándonos de él (en el doble sentido del "cuidarse de": cuidarse de aquello que nos insta porque nos ocurre, y a la vez cuidar de aquello que nos importa). Por esto, bien podría decirse que las cosas están henchidas de mundo, articuladas y como transidas de él, esto es: embebidas en una red de significatividad. Las cosas no son entes macizos y mostrencos, sino casos: ocasiones de tierra y cadencias del decir y el hacer humanos. Y la obra de arte es por así decir la condición de posibilidad de las cosas de mundo y tierra: no "cosas" superiores que marquen el paso a seguir, ni tampoco expresiones del alma o del espíritu de los hombres (y menos, de un pueblo señalado), sino lugares de encuentro. Lugares-límite,

${ }^{34}$ Por cierto, he reencontrado el Te Deum de San Bernardo (1319): Non nobis Domine, non nobis / sed Nomine Tuo da Gloriam (mencionado en Enrique V, de Shakespeare) en el blog: http://micatapulta.blogspot, de inspiración católica y patriótica. 
lugares que se abren al límite, a los bordes y recogen y acogen a su modo el afuera. Ese "modo" es el artista, siempre fuera de sí, volcado al afuera; siempre al pie de obra, configurando mundo ${ }^{35}$.

Pero entonces, ¿qué es el mundo, o mejor: qué es Mundo (singulare tantum)? Desde luego, no un lugar, ni el sitio o receptáculo en el que se encuentran los lugares (dentro de los cuales estarían las cosas, etc.). El mundo es, ya lo hemos insinuado, apertura que, de vez en vez, da espacio y respiro a las cosas, a través del quehacer humano (los animales y los vegetales están en el mundo, pero no son-de-Mundo (incluso en el lenguaje ordinario se dice de alguien que tiene muchas relaciones que es "una persona de mundo"). Según la relación entre mundo, tiempo y obra que venimos realizando al hilo del quehacer artístico de Chillida, puede decirse que, a redrotiempo, Mundo es aquello que permite interpretar (e.d.: "poner en su sitio") lo acaecido (algo que ha "pasado") como un "suceso" (successus, algo que "resulta": de ahí, "éxito", "prosperidad"). En cambio, a contratiempo, Mundo es aquello que permite retrotraer un suceso a un "evento" (eventum es la "consecuencia" de algo; es el participio pasado de evenire, lo acontecido a partir de algo). Ambos, contratiempo y redrotiempo, se dan al instante y como instante. Por el contrario, futuro y pasado se dan ahora, en el presente. Y el mundo queda entonces achatado, tan irrelevante como un conjunto o arsenal de cosas (incluyendo en ellas a los hombres): eso que suele llamarse también: el universo.

Pero si Mundo no es ni sitio, ni lugar, ni cosa ni conjunto de cosas, sino que, más bien al contrario, es en las "cosas" donde aquél comparece, según el significado originario de "cosa": "asamblea, reunión" de hombres-y-bienes (ingl. thing, lat. causa, gr. ekklesía); si son las cosas quienes dejan ver Mundo, mientras que la obra de arte lo configura: ¿qué puede querer decir entonces eso de "Mundo"?

Creo que puede ser oportuno denominar a esa conjunción de disyunciones y remisiones: Vacio. No, como se apuntó al inicio, vacío como privación o falta de cosas (en el Mundo nunca faltan “cosas”), ni vacío en cuanto recipiente a llenar con algo externo y ajeno al mismo (como una jarra de buen vino, por ejemplo $\left.{ }^{36}\right)$, sino Vacío como kénosis, como acción de "vaciar" que es, al mismo tiempo, positiva concesión de espacios a las cosas. Un Vacío que, como

\footnotetext{
${ }^{35}$ Cfr. Heidegger, Die Grundbegriffe der Metaphysik. Welt - Endlichkeit - Einsamkeit (= GM), Frankfurt/M., Klostermann, 1983, Gesamtausgabe 29/30.

${ }^{36}$ Repárese en que la jarra es jarra de veras sólo cuando desde ella se escancia en un vaso. Y el vino es vino de veras sólo cuando se bebe. El vacío es en todo caso una donación, un trasiego que da lugar a una acción humana, y no algo que estuviera debajo o detrás de las cosas, como el famoso hueco que -según cuentan sus discípulos- el encendedor de Oteiza habría dejado, al ser "despachado" éste de un manotazo para que hiciera su fugaz aparición el vacío "interior".
} 
el ser aristotélico, se dice de muchas maneras. Las maneras en que y con las que el hombre se las ha con la realidad. Pero, de entre esas maneras, sólo una deja ver el Vacío in actu exercitu: en el acto, y al instante. Esa manera es el arte $\mathrm{y}$, señaladamente, la poesía y la escultura plástica, no imaginera ni figurativa, sino la pura construcción de vacios, donde dejar ser a las cosas en su rico entramado. ${ }^{37} \mathrm{Y}$ en efecto, como se preguntaba Chillida: " ¿No son la construcción y la poesía componentes esenciales de todas las artes?"

No quisiera desde luego que se viera en esta descripción (no "definición") de Mundo como Vacío una suerte de elucubración metafísica, y menos mística. El Vacío que es Mundo se deja ver si y sólo si un grupo humano, enraizado en la tierra y luchando contra el tiempo y desde el tiempo que se ha ido sedimentando en él como usanza y tradiciones, es capaz de honrar a sus muertos y de trabajar solidariamente en pro de un quehacer común y compartido. El Mundo se dice de muchas maneras, se advirtió: y la manera artística hace del Mundo la: "localidad de los lugares, desde donde se irradia la posibilidad de que el hombre habite en medio de las cosas." ${ }^{38}$

El habitar sólo se logra en la comunidad, y en un pueblo histórico. No se trata de abstracción alguna, sino de un quehacer ético-político, en el cual tiene una función señalada el artista o poietés, porque es éste el que forja lugares de encuentro, lugares de convivencia, a través del recuerdo del dolor compartido: como el del devastado y ultrajado hogar de nuestros padres, tras el bombardeo de Gernika, convertida ahora la brecha en lóbulos que comunican el hogar con el entorno natural, estableciendo además un eje con la Casa de Juntas de Euskadi.

O bien, atendiendo ahora a la vida cotidiana, en medio del tráfago de la ciudad, el estar a contra-tiempo se plasma en la interrupción del paseo, en la perentoriedad que te incita a atender a un posible proyecto de vida en común, cuando la gente, la buena gente se reúna en una cordial excavación (recuérdese el tercer significado de "esculpir") en la tierra vasca; inversión del cenotafio: no es un volumen que oculta un vacío, sino un vacío disperso en varias estancias (no hay centro): un vacío que abre y convoca a la gente para que ocupe las gradas (también y sobre todo para la charla amistosa o el juego de los niños), como en la Plaza de los Fueros (o lo que es lo mismo: de las

\footnotetext{
${ }^{37}$ El arte y el espacio, ed. cit., p. 137: "La plástica: acción de corporeizar la verdad del ser en la obra, que instaura lugares." (p. 137).

${ }_{38}^{38}$ Ibidem, p. 133: "La plástica sería (adviértase el modo en potencial, F.D.) un corporeizar lugares que, al abrir una comarca y preservarla, mantienen congregado en torno a sí un [ámbito] libre que concede un demorarse a las cosas según el caso, y habitación al hombre en medio de las cosas."
} 
Libertades), en Vitoria/Gasteiz, en colaboración con Luis Peña Ganchegui. Allí, en un ángulo, con pudor, se alza la Estela de los Fueros: un símbolo de comunión, en una suerte de hornacina, pero a la altura de los ojos y al alcance de la mano: una suerte de táctil altar laico, con las tres ramas superiores de la pilastra de acero cortén fundiéndose en un abrazo. Y uno no puede por menos de recordar entonces las palabras de Heidegger: "En el lugar juega el congregar, entendido en el sentido del albergar que deja libres a las cosas en su comarca" 39 .

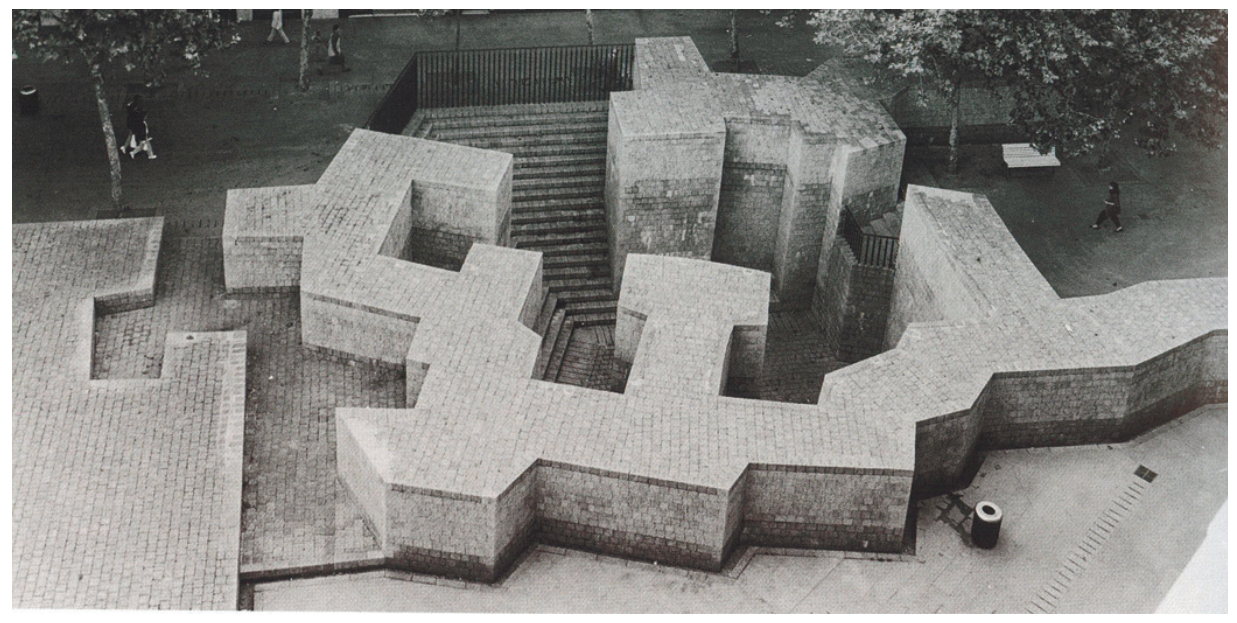

Chillida. Monumento a los Fueros Vascos (Vitoria)

Dejar libres a las cosas es dejarlas que tejan metáforas imprevistas, desplazamientos antes impensados; antes, cuando nos empeñábamos en poner cada cosa en su sitio. Metáforas condensadas en un espejearse poema y obra, como en la admirable serie de xilografías (algunas, sin tinta) de 1973 para el poema Más allá, con el que se abre Cántico, de Jorge Guillén; será allí donde encontremos con mayor fuerza y a la vez elegancia esa gravitación de lo leve, en la cual se ponen de relieve las huellas del vacío, erigidas a través de un juego sutil de densidad y presión. Allí donde el instante mismo parece estar como conjugado, meramente insinuado en perfiles que se dan la palabra y la figura evanescente, como en las xilografías (algunas, sin tinta: pura gravidez ingrávida) para el poema "Más allá", con que se abre Cántico de Jorge Guillén, en su versión de 1973.

${ }^{39}$ Op.cit., p. 129. 
Y por un filo escueto,

$\mathrm{O}$ el amor de una curva

de asa, la energía

De plenitud actúa.

¡Energía o su gloria!

[...]

Y ágil, humildemente,

La materia apercibe

Gracia de Aparición. ${ }^{40}$

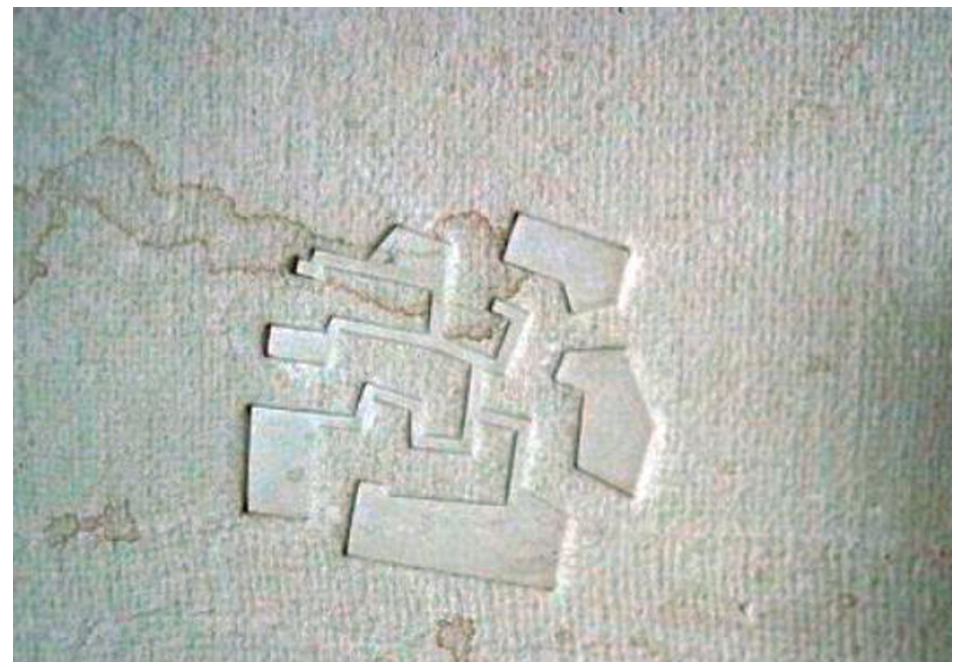

Xilografía para "Más Allá”, de Jorge Guillén

En esta línea, en estas líneas: ¿cómo no admirar también la perfecta conjunción -que tanto habría placido a Heidegger- de mano, dibujo y poema que aparece en los homenajes de Chillida a San Juan de la Cruz? ¿Cómo no contornear los perfiles en los que se confunden las manos del artista con las montañas evocadas por el poeta de lo Sagrado, allí donde se ensalza dolorosamente la huella de una ausencia? (Recuérdese: "salí tras ti clamando, y ya eras ido").

Aquí, las líneas de la mano se convierten en perfiles orográficos, evocados a su vez por los versos del Cántico espiritual: "Mi amado, las montañas, / los

${ }^{40}$ Más allá. IV, estr. 3, 4 y 5. (Cántico. 3ª ed. completa. Sudamericana. Buenos Aires 1973). 
valles solitarios nemorosos, / las ínsulas extrañas, / los ríos sonorosos, / el silbo de los aires amorosos." Ahora, el dibujo parece que quisiera también él lanzarse al vuelo: escultura cuyo peso diríase negativo: aquí, al fin, libres de toda materia y aun de toda Gravitación, parecemos hallarnos frente a un libre juego de transacciones, de remisiones: como en una suerte de Gesamtkunstwerk, en donde el arte se cumpliera... a fuerza de vaciarse casi literalmente, de anonadarse en la blancura mística de la nada.

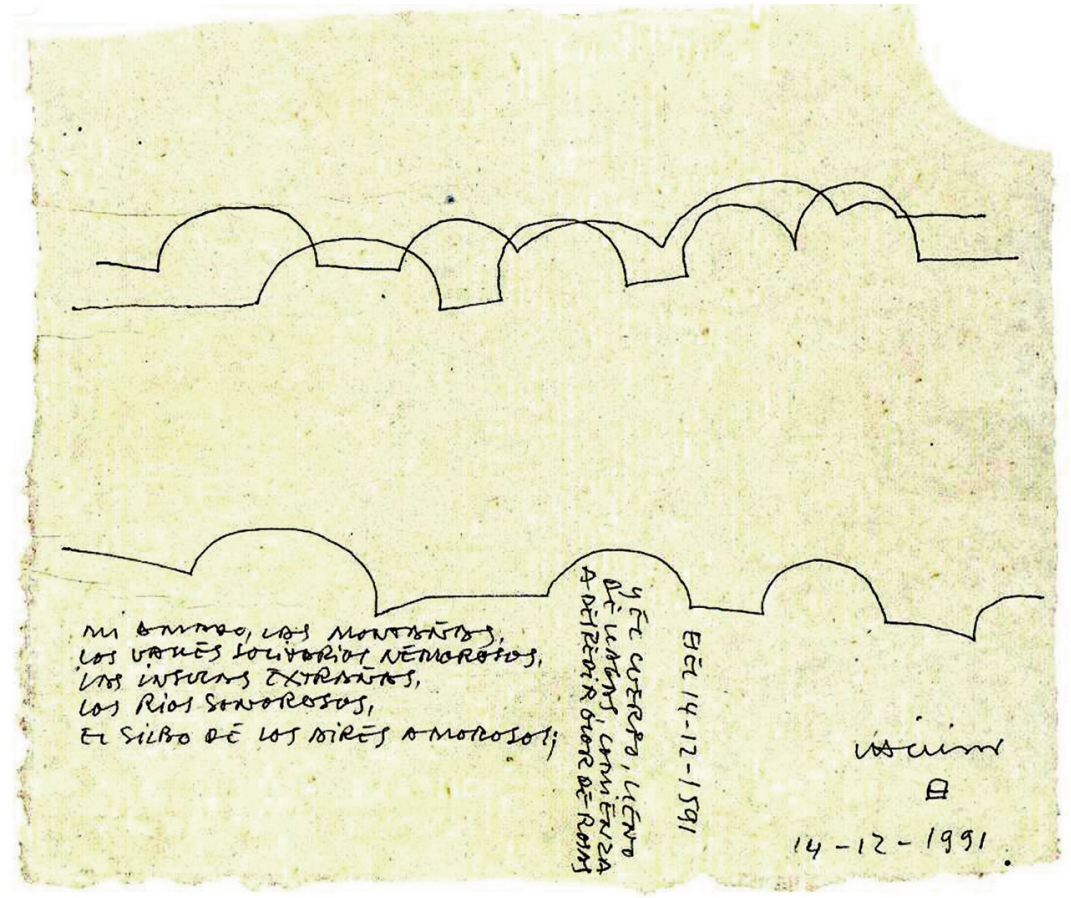

Chillida. Dibujo para el "Cántico espiritual” de S. Juan de la Cruz

Todo ello sería, sin embargo, demasiado irenista, demasiado edificante, si no fuera porque el poeta está aquí convocado de cuerpo presente. Chillida escribe, dibuja, deja que las letras se alcen como diminutos collados para poner de relieve, verticalmente, el contrapunto de la sensual enumeración de las bellezas de la tierra. Ese contrapunto es, literalmente, el contra-tiempo absoluto: la muerte. La muerte del propio Santo, aquí también llevada a presencia a redrotiempo, en el día instante en que se cumplen los cuatrocientos años de su muerte: "El cuerpo -se dice al margen-, lleno de llagas, comienza a despedir olor de rosas." Adviértase: es la putrefacción misma del cuerpo, no su "salvación" como cuerpo intacto - o sea, naturalmente "embalsamado"- la que 
despide el aroma. No la cruz en la rosa del presente, como querían Goethe y Hegel, sino: la cruz es la rosa del instante. Pues es sólo la súbita irrupción de la falta-de-tiempo la que permite y propicia a la vez la expansión del perfume que penetra en otros cuerpos y los lleva a comunión, en la solidaridad con la propia muerte, en la anticipación de la muerte propia. El olor desprendido de la falta.

En el cuerpo alientan las llagas, al igual que en la obra medran, roedoras, las fisuras producidas por la erosión y el desgaste del tiempo. Así también, las construcciones del arquitecto del vacío dejan ver, hacen ver las grietas que amenazan a la obra, la "fatiga" de los materiales y el cansancio de los hombres: la terrible y hermosa carga de la convivencia en la diferencia y en la disensión. Como en el Monumento a la tolerancia, en Sevilla, cabe el solar ocupado por el edificio de la Santa Inquisición. Pues tolerar no es dejar que todo siga igual, y que así nada valga: tal el vacío estúpido de una concordia huera. Tolerar es también y sobre todo soportar, padecer la irrupción violenta del tiempo, del vacio instante, de ese instar que adviene y amenaza, y que por ello incita a la solidaridad entre mortales. No hay congregación sin recuerdo; y a la vez, indisolublemente, sin premonición de la falta. 